\title{
Tuberculosis treatment outcome monitoring in European Union countries: systematic review
}

\author{
Rob van Hest*\#, Csaba Ködmön`, Suzanne Verver*, Connie G.M. Erkens*, \\ Masja Straetemans ${ }^{*,+}$, Davide Manissero ${ }^{\star}$ and Gerard de Vries*
}

ABSTRACT: Treatment success measured by treatment outcome monitoring (TOM) is a key programmatic output of tuberculosis (TB) control programmes. We performed a systematic literature review on national-level TOM in the 30 European Union (EU)/European Economic Areas (EEA) countries to summarise methods used to collect and report data on TOM.

Online reference bibliographic databases PubMed/MEDLINE and EMBASE were searched to identify relevant indexed and non-indexed literature published between January 2000 and August 2010.

The search strategy resulted in 615 potentially relevant indexed citations, of which 27 full-text national studies (79 data sets) were included for final analysis. The selected studies were performed in $10 \mathrm{EU} / \mathrm{EEA}$ countries and gave a fragmented impression of TOM in the EU/EEA. Publication year, study period, sample size, databases, definitions, variables, patient and outcome categories, and population subgroups varied widely, portraying a very heterogeneous picture.

This review confirmed previous reports of considerable heterogeneity in publications of TOM results across EU/EEA countries. PubMed/MEDLINE and EMBASE indexed studies are not a suitable instrument to measure representative TOM results for the 30 EU/EEA countries. Uniform and complete reporting to the centralised European Surveillance System will produce the most timely and reliable results of TB treatment outcomes in the EU/EEA.

KEYWORDS: Cohort analysis, death, failure, surveillance, treatment success, tuberculosis control

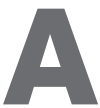

ttention to tuberculosis (TB) control in the European Union (EU) and European Economic Areas (EEA) has been raised in recent years through a number of initiatives, including the launching of the Framework Action Plan to Fight Tuberculosis in the EU [1-3]. Among the key issues underlined in the action plan is the need to achieve and sustain acceptable levels of treatment success among all TB patients. Treatment success, measured by a standardised process of treatment outcome monitoring (TOM), is a key programmatic output of any TB control programme [3]. In 1998, a World Health Organization (WHO) and European region of the International Union against Tuberculosis and Lung Disease (IUATLD) working group published a consensus statement on standardised TOM in Europe [4]. While clinicians need to know treatment success in individual patients, TOM is essential for countries to systematically evaluate the effectiveness of the national TB programme. In the $\mathrm{WHO} / \mathrm{IUATLD}$ recommendations emphasis was placed on cohort analysis of definite, i.e. culture-confirmed, cases of pulmonary TB. The initial purpose of TOM was to find out how many of the potentially infectious TB patients notified were declared "cured" at the end of treatment [4]. More recently, treatment "success" has been measured, combining the number of patients being "cured" and those having their "treatment completed" [5].

Since January 1, 2008, the European Centre for Disease Prevention and Control (ECDC) and the WHO Regional Office for Europe have jointly coordinated TB surveillance in Europe. Designated national surveillance institutions or individuals in each EU/EEA member state are responsible for providing the data, which are reported to the European Surveillance System (TESSy). Since 2002, TOM data have been collected for the year cohort of individual cases 12 months after reporting to TESSy, and since 2008 for multidrug-resistant (MDR)-TB treatment outcome for cases in the year
AFFILIATIONS

*KNCV Tuberculosis Foundation, The Hague,

\#Tuberculosis Control Dept, Municipal Public Health Service, Rotterdam, and

+KIT Biomedical Research, Royal Tropical Institute, Amsterdam, The Netherlands.

'European Centre for Disease Prevention and Control, Stockholm, Sweden.

CORRESPONDENCE

C. Ködmön

European Centre for Disease

Prevention and Control

Tomtebodavägen $11 \mathrm{~A}$

S-171 83 Stockholm

Sweden

E-mail: Csaba.Kodmon@

ecdc.europa.eu

Received:

Feb 212012

Accepted after revision:

June 072012

First published online:

July 122012

This article was modified in April 2016 to correct errors in the licence information. 
cohort 24 months after reporting to TESSy. However, the definitions applied for TOM seem to vary between countries, as do data collection methods. A recently published analysis of TOM within the EU/EEA expressed concern about only marginal improvement in the number of reporting countries and concluded that the importance of TOM needs to be further stressed and mechanisms should be explored to maximise progress [3].

We performed a systematic literature review on TOM at the national level in the 30 EU/EEA member states to: 1) summarise the methods used to collect and report data on TOM; 2) examine reports on TOM proportions calculated for the general population, vulnerable populations, MDR-TB/ extensively drug-resistant (XDR)-TB subcohorts and other identifiable subgroups; and 3) find additional TOM information not available in TESSy.

\section{METHODS}

\section{Literature search strategy}

Online reference bibliographic databases PubMed/MEDLINE and EMBASE were searched to identify relevant indexed studies published between January 2000 and August 2010. The search strategy consisted of a search only including medical subject headings (MeSH) terms "treatment outcome" AND "tuberculosis" AND any of the 30 EU/EEA countries (Austria, Belgium, Bulgaria, Cyprus, Czech Republic, Denmark, Estonia, Finland, France, Germany, Greece, Hungary, Iceland, Ireland, Italy, Latvia, Liechtenstein, Lithuania, Luxembourg, Malta, the Netherlands, Norway, Poland, Portugal, Romania, Slovakia, Slovenia, Spain, Sweden, UK) combined with (OR) a search including the same terms as free text terms. Exploration of the search strategy revealed that when including a MeSH term relating to study design (e.g. cohort studies, follow-up studies, longitudinal studies) some relevant articles were excluded, and so as to ensure maximum sensitivity of the search strategy, this study design MeSH term was not included. The electronic search was supplemented by hand-searching reference lists of identified eligible studies and relevant review articles. Furthermore, national focal persons in the 30 EU/EEA member states were asked to provide recent reports including actual nationwide TOM data or other relevant non-indexed publications regarding TOM. The search strategy was limited to indexed and non-indexed literature published since 2000, 2 yrs after publication of the recommendations of the WHO/ IUATLD working group for uniform reporting by cohort analysis of treatment outcomes in TB patients [4], and literature published in English, German, Dutch, Swedish, French and Spanish (or translation into one of these languages by the national focal persons).

\section{Inclusion criteria and study selection}

Inclusion criteria for systematic review were: 1) retrospective and prospective cohort studies conducted in EU/EEA member states; 2) reporting TB TOM data (expressed as a percentage of the total number of notified cases starting TB treatment) in at least two of the initial six categories (cured, treatment completed, treatment failure, death, treatment interrupted (default) and transferred out) as recommended by WHO/IUATLD [4]; 3) studies including data at the national level; and 4) studies on TB patients meeting either the $\mathrm{WHO}$ recommended definitions for "definite cases" or "other than definite cases" [4, 6] or TB patients meeting the possible, probable or confirmed case definition as published by the European Commission in 2008 [7].

Articles categorised as editorials, comments, reviews, case studies and/or drug efficacy tested in vitro or through clinical trial were excluded from systematic review. Citations identified by the search strategy were reviewed for possible eligibility by one author (M. Straetemans) based on title and abstract, according to the inclusion criteria. When identified as such, attempts were made to obtain the full text of the article and subsequently reviewed for eligibility by one of the researchers (M. Straetemans).

\section{Data extraction}

Two researchers (M. Straetemans and R. van Hest) extracted the data from the included studies and entered them into Excel (Microsoft Corporation; Redmond, WA, USA). No attempts were made to obtain missing data from the researchers of eligible studies. Quality assessment of the included studies was not performed because existing tools were either not considered relevant for the articles and reports identified by this systematic review or would result in large variability [8].

The treatment outcome categories were formulated according to international recommendations (cured, treatment completed, treatment failure, death, treatment interrupted (default) and transferred out) [4], with the addition of three categories "still on treatment", "unknown" and "successful" [3, 7]. The adapted definitions have been used in previous analyses of TB treatment outcomes in the EU and EEA [3, 9]. Categories not in these definitions were mentioned separately. For MDR-TB/ XDR-TB patients, the outcomes were measured reflecting the definitions proposed by LASERSON et al. [10] and published in WHO guidelines [11], which are similar to the approach taken in a previous systematic review on treatment outcomes of MDR-TB [12]. An overview of all data and outcome categories extracted is available from the authors.

\section{RESULTS}

\section{Study selection process}

In the systematic literature search, initially 615 potentially relevant indexed citations were retrieved from electronic databases and other sources. After inspection of the titles and abstracts, 530 articles were excluded. Of the 85 articles remaining for full-text screening on eligibility criteria, 12 articles could not be retrieved, despite requests to national focal persons. Of the 73 remaining articles, 19 articles were further excluded after more in-depth scrutiny. Of the 54 remaining full text articles, 27 (79 data sets) were national studies and included for further analysis. One article could contain more than one data (sub)set, i.e. presenting treatment outcomes for more types of TB or for more subgroups of the population. The study selection process is shown in detail in figure 1.

\section{Characteristics of selected studies}

An overview of the 27 selected national studies on TOM in EU/EEA countries is presented in table $1[3,13-38]$. The articles were from 10 EU/EEA countries (UK $(n=6,21 \%)$, Latvia $(n=5,18 \%)$, Estonia $(n=4,14 \%)$, the Netherlands $(n=3$, $11 \%)$, Denmark $(n=2,7 \%)$ and one study each $(4 \%)$ from the 


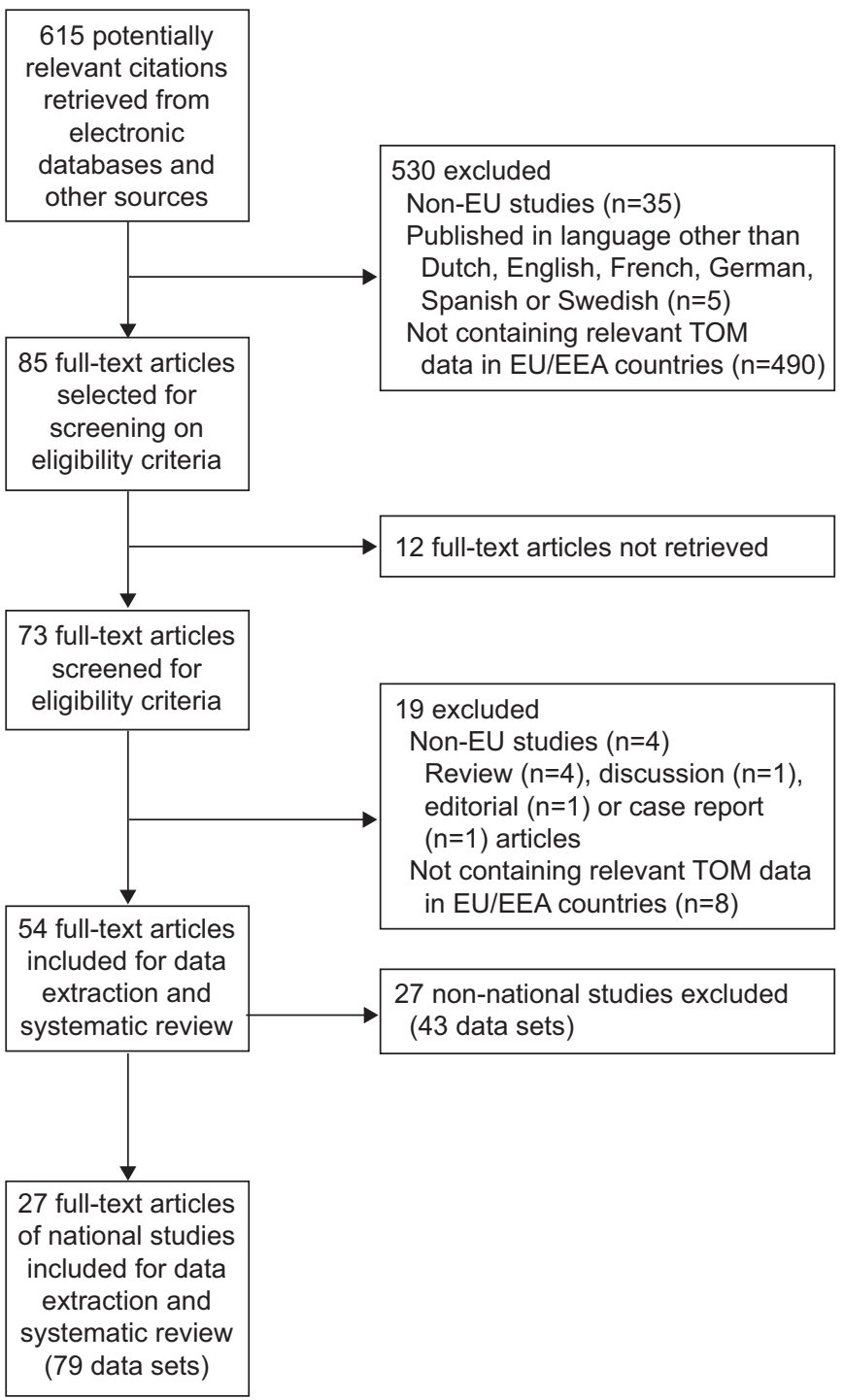

FIGURE 1. The selection process of articles included in the systematic review. EU: European Union; TOM: treatment outcome monitoring; EEA: European Economic Area.

Czech Republic, Finland, Norway, Romania and Sweden). Three studies presented EU/EEA-wide data. One article described data from two EU/EEA countries. The types of TB, publication year and study period, as well as sample size and TOM categories of patients reported varied widely.

\section{Cohort analysis and data sources of selected studies}

Retrospective cohort analysis was performed by 25 (93\%) studies and two $(7 \%)$ articles described a prospective cohort analysis. Electronic TB databases were used by $21(84 \%)$ studies, electronic mycobacterial laboratory databases by 12 $(44 \%)$ studies, hospital records by seven (26\%) studies, civil registration sources, such as death registries, by six $(22 \%)$ studies, clinicians were contacted in three $(11 \%)$ studies, and an AIDS registry and patient interviews were used by one $(4 \%)$ study. Multiple data sources for the TOM reports were used by 13 studies. Two studies did not report the data sources used.
Five described (partly) $\geqslant 10$-yr-old TOM data, 17 studies described (partly) 5-10-yr-old TOM data and three studies described data $<5$ yrs old.

\section{TOM definition of selected studies}

Three $(11 \%)$ studies used a WHO or EU TB case definition with references, two $(7 \%)$ studies used a WHO TB case definition but gave no reference, four (15\%) studies seemed to use a WHO or EU case definition with an indirect reference and 18 $(67 \%)$ studies implicitly used a WHO or EU TB case definition (but without a reference) because they described culturepositive TB cases.

\section{Completeness of demographic and TOM interval variables and heterogeneity}

$14(52 \%)$ studies mentioned the proportion of males in the study population and seven (26\%) studies reported the average age of the patient population. $14(52 \%)$ studies reported the time interval of TOM reporting after diagnosis or notification. The 79 datasets extracted described very heterogeneous patient populations, subdivided into 41 categories of type of TB (overview of categories available from the authors).

\section{TOM categories in the selected studies}

TOM results were reported in 12 categories, of which nine were in the list of definitions used (table 1). The number of data sets reporting at least one patient to one of the nine defined categories varied between 15 (unknown) and 69 (died) (table 2). The range of the minimum and maximum proportion of patients reported in each category varied widely between the various data sets.

\section{TOM among subgroups in the selected studies}

TOM results were presented for various subgroups of the population but varied between the selected national studies. Nine (33\%) studies presented TOM results by age groups, eight $(30 \%)$ studies by sex and eight $(30 \%)$ studies by nationality or country of birth. $15(56 \%)$ studies presented TOM results for pulmonary TB and six (22\%) studies for extrapulmonary TB. 14 $(52 \%)$ studies presented TOM results for new TB cases and eight $(30 \%)$ studies for retreatment TB cases. 14 (52\%) studies presented TOM results for MDR-TB cases and three $(11 \%)$ studies for XDR-TB cases.

\section{TOM among vulnerable subgroups in the selected studies}

For certain marginalised risk groups, TOM results, often a single outcome, such as death or default, were presented for HIV seropositive TB cases by four (15\%) studies, for homeless TB cases by three $(11 \%)$ studies and for TB in prisoners by two $(7 \%)$ studies. None of the studies mentioned TOM results for intravenous drug users specifically. Incidentally, TOM results were presented for various other subgroups such as asylum seekers, travellers, alcoholics, illicit drug users and persons using immunosuppressive medication.

\section{TOM for MDR-TB and XDR-TB in the selected studies}

MDR-TB data were reported in 14 studies (one study reported for two countries) from six member states: Estonia $(n=4)$, Latvia $(n=4)$, UK $(n=4)$, Denmark, the Netherlands and Sweden $(n=1$ each). Three of these countries reported 2006 cohort MDR-TB TOM outcomes to TESSy [3]. The number of 


\begin{tabular}{|c|c|c|c|c|c|c|}
\hline First author [ref.] & Country & Type of TB & $\begin{array}{c}\text { Year of } \\
\text { publication }\end{array}$ & Study years & $\begin{array}{c}\text { Sample size } \\
n\end{array}$ & TOM categories of patients reported \\
\hline ABUBAKAR [13] & UK & XDR-TB & 2009 & 1995-2008 & 8 & Death, ongoing ${ }^{\#}$ \\
\hline ABUBAKAR [14] & $\begin{array}{l}\text { England and } \\
\text { Wales }\end{array}$ & Paediatric TB & 2008 & $2001-2005$ & 1941 & $\begin{array}{l}\text { Completed, died, transferred out, ongoing, } \\
\text { lost to follow-up, unknown, stopped }\end{array}$ \\
\hline ANDERSON [15] & Scotland & MDR-TB & 2009 & 2000-2007 & 11 & $\begin{array}{c}\text { Completed, ongoing, lost to follow-up, } \\
\text { unknown }\end{array}$ \\
\hline ANTOINE [16] & $\begin{array}{l}\text { England, Wales } \\
\text { and Northern } \\
\text { Ireland }\end{array}$ & All TB & 2007 & 2001 & 5139 & $\begin{array}{l}\text { Completed, died, transferred out, ongoing, } \\
\text { lost to follow-up, unknown, treatment } \\
\text { stopped, treatment incomplete }\end{array}$ \\
\hline BANG [17] & Denmark & $\begin{array}{l}\text { Culture-confirmed } \\
\text { relapse TB, }\end{array}$ & 2010 & 1992-2005 & 54 & $\begin{array}{l}\text { Success (cured and completed), failed, } \\
\text { died, default }\end{array}$ \\
\hline BANG [18] & Denmark & MDR-TB & 2010 & 1992-2007 & 29 & $\begin{array}{l}\text { Cured, completed, default, transferred out, } \\
\text { unknown, success (after initial defaulting) }\end{array}$ \\
\hline BORGDORFF [19] & The Netherlands & $\begin{array}{l}\text { All TB with treatment } \\
\qquad<1 \mathrm{yr}\end{array}$ & 2000 & 1993-1997 & 6690 & Completed, died, default, transferred out \\
\hline BWIRE [20] & The Netherlands & $\begin{array}{l}\text { All bacteriologically con- } \\
\text { firmed TB }\end{array}$ & 2000 & 1993-1996 & 3217 & $\begin{array}{l}\text { Success (cured and completed), died, } \\
\text { default, transferred out }\end{array}$ \\
\hline DIтAH [21] & $\begin{array}{l}\text { England, Wales } \\
\text { and Northern } \\
\text { Ireland }\end{array}$ & All TB & 2008 & $2001-2002$ & 10684 & $\begin{array}{l}\text { Cured, completed, died, transferred out, } \\
\text { ongoing, lost to follow-up, unknown }\end{array}$ \\
\hline FALZON [22] & $\begin{array}{l}19 \mathrm{EU} / 20 \mathrm{EEA} \\
\text { countries }\end{array}$ & $\begin{array}{l}\text { New pulmonary culture- } \\
\text { confirmed TB }\end{array}$ & 2006 & 2000-2001 & 23909 & $\begin{array}{l}\text { Success (cured and completed), died, } \\
\text { default, transferred out }\end{array}$ \\
\hline FARAH [23] & Norway & $\begin{array}{l}\text { New pulmonary culture- } \\
\text { confirmed TB }\end{array}$ & 2005 & 1996-2002 & 655 & $\begin{array}{c}\text { Cured, completed, failure, died, default, } \\
\text { transferred out }\end{array}$ \\
\hline Geerligs [24] & The Netherlands & MDR-TB & 2000 & 1985-1998 & 44 & Cured, died, ongoing \\
\hline HoLtz [25] & Latvia & Pulmonary MDR-TB & 2006 & 2000 & 167 & Cured, completed, failure, died, default \\
\hline KLIIMAN [26] & Estonia & $\begin{array}{l}\text { All pulmonary culture- } \\
\text { confirmed TB }\end{array}$ & 2010 & 2003-2005 & 1107 & Cured, completed, failure, died, default \\
\hline KLIIMAN [27] & Estonia & All pulmonary XDR-TB & 2009 & 2003-2006 & 54 & Cured, completed, failure, died, default \\
\hline LeIMANE [28] & Latvia & All pulmonary MDR-TB & 2005 & 2000 & 204 & Cured, completed, failure, died, default \\
\hline LOCKMAN [29] & Estonia & New pulmonary pan- & 2001 & 1994-1996 & 92 & Cured, failure, died, stopped \\
\hline
\end{tabular}

\begin{tabular}{|c|c|c|c|c|c|c|}
\hline \multirow[b]{2}{*}{ MARICA [30] } & \multicolumn{3}{|c|}{ 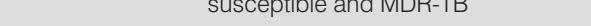 } & \multirow[b]{2}{*}{2006} & \multirow[b]{2}{*}{ Not reported } & \multirow[b]{2}{*}{ Cured (proportion), completed (proportion) } \\
\hline & Romania & $\begin{array}{l}\text { New culture-confirmed } \\
\text { TB and new sputum- } \\
\text { smear positive TB }\end{array}$ & 2009 & & & \\
\hline NATHANSON [31] & Estonia and Latvia & MDR-TB & 2006 & $\begin{array}{l}2001 \text { (Estonia); } \\
\text { 2000-2001 } \\
\text { (Latvia) }\end{array}$ & 291 & Cured, completed, failure, died, default \\
\hline ORMEROD [32] & $\begin{array}{l}\text { England and } \\
\text { Wales }\end{array}$ & $\begin{array}{c}\text { Pulmonary and lymph } \\
\text { node TB (including } \\
\text { deaths) }\end{array}$ & 2003 & $\begin{array}{l}1998 \text { (first } \\
6 \text { months) }\end{array}$ & 1337 & $\begin{array}{l}\text { Cured, completed, failure, died, default, } \\
\text { transferred out, lost to follow-up }\end{array}$ \\
\hline RIEKSTINA [33] & Latvia & $\begin{array}{l}\text { New bacteriologically } \\
\text { confirmed pulmonary TB }\end{array}$ & 2007 & 2002 & 934 & $\begin{array}{l}\text { Cured, completed, failure, died, default, } \\
\text { transferred out, ongoing }\end{array}$ \\
\hline RoMANUS [34] & Sweden & All TB & 2000 & 1994-1995 & 676 & $\begin{array}{l}\text { Cured, died, default, transferred out, } \\
\text { ongoing, unknown, initial defaulting, stopped }\end{array}$ \\
\hline TRNKA [35] & Czech Republic & $\begin{array}{l}\text { New bacteriologically } \\
\text { confirmed pulmonary TB }\end{array}$ & 2001 & 1998 & 731 & $\begin{array}{l}\text { Cured, completed, failure, died, default, } \\
\text { transferred out, unknown }\end{array}$ \\
\hline FALZON [38] & 19 EU countries & $\begin{array}{l}\text { New pulmonary culture- } \\
\text { confirmed TB }\end{array}$ & 2007 & 1999-2003 & 17253 & Success (proportion), died (proportion) \\
\hline
\end{tabular}




\section{TABLE 1 Continued}

\begin{tabular}{|c|c|c|c|c|c|c|}
\hline First author [ref.] & Country & Type of TB & $\begin{array}{c}\text { Year of } \\
\text { publication }\end{array}$ & Study years & $\begin{array}{c}\text { Sample size } \\
n\end{array}$ & TOM categories of patients reported \\
\hline MANISSERO [3] & $\begin{array}{c}22 \text { EU/EEA } \\
\text { countries }\end{array}$ & $\begin{array}{c}\text { All pulmonary } \\
\text { culture-confirmed TB }\end{array}$ & 2010 & 2007 & 36377 & $\begin{array}{l}\text { Success (cured and completed), failure } \\
\text { died, default, transferred out } \\
\text { (including unknown), ongoing }\end{array}$ \\
\hline
\end{tabular}

TB: tuberculosis; XDR: extensively drug resistant; MDR: multi-drug resistant. ${ }^{*}$ : ongoing, still receiving treatment.

patients per study could be limited or the data relatively old, e.g. the four studies from the UK reported eight XDR-TB cases, 11 MDR-TB cases, 18 MDR-TB cases and 41 MDR-TB cases, respectively, partially overlapping, and the studies from the Netherlands and Sweden reported 44 MDR-TB cases (19851999) and three MDR-TB cases (1995), respectively.

\section{Extracted datasets of selected studies}

Of the 79 datasets, 13 were (partly) extracted from the WHO European region, i.e. countries outside the EU/EEA, or EuroTB or ECDC TOM overview articles using TESSy data, i.e. not from individual EU/EEA countries $[3,22,38]$. Of the remaining 66 datasets, $28(42 \%)$ came from eight studies reporting TOM outcomes for Latvia and Estonia for 1-, 2- or 3-yr periods. The other 38 datasets showed TOM results for various types of TB in eight member states. A total of $33(42 \%)$ out of the 79 datasets reported data on MDR-TB cases. Tables 3 and 4 show that of the 79 datasets extracted, relatively few (eight for (new) culturepositive pulmonary TB and seven for MDR-TB) could potentially be compared to similar TOM outcomes in one of the three EuroTB or ECDC overview articles using TESSy data [3, 22, 38]. Many of the published data are relatively old, especially for MDR-TB. For Estonia, the articles on culture-positive TB and MDR-TB reported considerably higher success rates compared to the latest EU/EEA data from TESSy.

\section{Reports and "grey" literature}

A request to 30 national focal persons of the EU/EEA member states to provide one or two most relevant non-indexed reports yielded nine reactions. Three national focal persons referred to their website for more information. Six articles were received but these referred to local or regional reports, were published after our literature search period, or did not contain TOM data. Three countries reported higher success rates compared to TESSy or earlier reports $[3,38]$ and two countries reported similar results.

\section{DISCUSSION}

\section{Main results}

TB treatment success in the EU/EEA, measured by a standardised process of TOM, is a key programmatic output. Systematic review of published TOM studies from EU/EEA member states reveals that: 1) only 27 eligible publications over a 10-yr period could be identified from 10 countries, widely varying in publication year, study period and sample size; 2) there is heterogeneity related to TOM methods, processes, policies and practices, e.g. regarding TOM databases, definitions, variables included, patient categories and outcome categories used, as well as population subgroups described, e.g. drug-resistance or vulnerable groups in society; 3 ) a fragmented presentation exists related to TOM results, with different numbers and types of outcome categories presented for different groups of TB patients,

TABLE 2 Number of data sets with treatment outcome categories reporting at least one patient and the proportion of the total number of data sets, with minimum and maximum proportions

\begin{tabular}{lcc} 
Treatment outcome category & Data sets with at least one patient reported & Minimum-maximum proportion of patients reported \% \\
\hline Cured & $53(67.1)$ & $10.0-89.0$ \\
Completed & $43(54.4)$ & $1.1-88.4$ \\
Failed & $49(62.0)$ & $0.2-68.0$ \\
Died & $69(87.3)$ & $0.7-28.3$ \\
Defaulted & $56(70.9)$ & $0.8-29.0$ \\
Transferred out & $31(39.2)$ & $0.3-11.7$ \\
Ongoing\# & $25(31.6)$ & $0.3-66.7$ \\
Unknown & $15(19.0)$ & $1.6-27.3$ \\
Success & $20(25.3)$ & $6.9-88.6$ \\
Lost to follow-up & $10(12.7)$ & $3.1-9.1$ \\
Stopped & $8(10.1)$ & $0.8-7.6$ \\
Treatment incomplete & $4(5.1)$ & $0.2-0.3$ \\
\hline
\end{tabular}

Data are presented as $\mathrm{n}(\%)$, unless otherwise stated. ${ }^{\#}$ : still on treatment; " ${ }^{\circ}$ cured and completed. 


\begin{tabular}{|c|c|c|c|c|c|c|c|}
\hline TABLE 3 & $\begin{array}{l}\text { Published treat } \\
\text { Union (EU)/Eur } \\
\text { Organization (V }\end{array}$ & $\begin{array}{l}\text { ment outcome monitoring } \\
\text { opean Economic Area cc } \\
\text { VHO) EU and EU TOM s }\end{array}$ & $\begin{array}{l}\text { TOM) repo } \\
\text { tries, pote } \\
\text { cess rates }\end{array}$ & $\begin{array}{l}\text { culture- } \\
\text { compar }\end{array}$ & $\begin{array}{l}\text { sitive pulmonary ti } \\
\text { e with previously }\end{array}$ & $\begin{array}{l}\text { uberculosis (TB) ir } \\
\text { eported World He }\end{array}$ & $\begin{array}{l}\text { European } \\
\text { alth }\end{array}$ \\
\hline ANTOINe [16] & UK & Culture-positive pulmonary TB & 2001 & 77 & NR & 65 & 77 \\
\hline KLIIMAN [26] & Estonia & $\begin{array}{c}\text { New culture-positive } \\
\text { pulmonary TB }\end{array}$ & 2000-2005 & 87 & $73 / 68$ & 70 & 61 \\
\hline KLIIMAN [27] & Estonia & $\begin{array}{c}\text { Retreatment culture-positive } \\
\text { pulmonary TB }\end{array}$ & 2000-2005 & 60 & NR & NR & 47 \\
\hline MARICA [30] & Romania & $\begin{array}{l}\text { New culture-positive } \\
\text { pulmonary TB }\end{array}$ & 2006 & 86 & NR & NR & 85 \\
\hline Romanus [34] & Sweden & Smear-positive pulmonary TB & $1994 / 1995$ & 69 & $79 / 62$ & 84 & 66 \\
\hline
\end{tabular}

Data are presented as \%. NR: not reported

also portraying a heterogeneous picture, prohibiting a useful metaanalysis of the results for the general population and population subgroups; 4) additional TOM information not available in TESSy is available in some member states but only sporadically published in the literature and in a fragmented and heterogeneous way; 5) for the general population, EuroTB and ECDC overviews are considerably more complete; and 6) TOM data on MDR-TB/ $\mathrm{XDR}-\mathrm{TB}$ are available for six countries, but again EuroTB and ECDC overviews are considerably more complete.

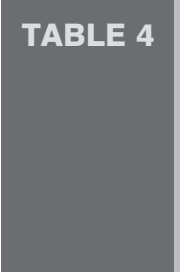

Published treatment outcome (TOM) monitoring reports of multidrug-resistant (MDR) tuberculosis (TB) in European Union (EU)/European Economic Area countries, potentially comparable with previously reported World Health Organization EU and EU TOM success rates

\begin{tabular}{|c|c|c|c|c|c|}
\hline Author & Country & Type of TB & Year & Success & EU 2007 [3] \\
\hline $\begin{array}{c}\text { ANDERSON } \\
{[15]}\end{array}$ & UK & MDR & 2000-2007 & 18.2 & NR \\
\hline $\begin{array}{c}\text { Geerligs } \\
\text { [24] }\end{array}$ & $\begin{array}{l}\text { The } \\
\text { Netherlands }\end{array}$ & MDR & 1985-1998 & 75 & NR \\
\hline HoLtz [25] & Latvia & MDR & 2000 & 64.7 & 61.3 \\
\hline $\begin{array}{c}\text { NATHANSON } \\
\text { [31] }\end{array}$ & Latvia & MDR & $2000 / 2001$ & 68.5 & 61.3 \\
\hline $\begin{array}{l}\text { LeIMANE } \\
\text { [37] }\end{array}$ & Latvia & MDR & 2000-2003 & 67 & 61.3 \\
\hline $\begin{array}{c}\text { NatHANSON } \\
\text { [31] }\end{array}$ & Estonia & MDR & 2001 & 65.2 & 45.3 \\
\hline $\begin{array}{c}\text { RoMANUS } \\
\text { [34] }\end{array}$ & Sweden & MDR & $1994 / 1995$ & 33 & NR \\
\hline
\end{tabular}

Data are presented as \%. NR: not reported

\section{Limitations}

Apart from the three EuroTB and ECDC overviews, only 24 studies from $10 \mathrm{EU} / \mathrm{EEA}$ countries were identified, which are unlikely to be representative for the study area and period. Because of the practices observed in routine TOM data collection and reporting, selection and publication bias cannot be excluded, e.g. because of design, funding and staffing of the studies. Full text of 12 potential eligible studies could not be obtained but inspection of the title and abstract revealed that the majority were regional or local studies or comments. Three of the articles were published at least 7 yrs ago. We consider it unlikely that the availability of these articles in full would have influenced the outcomes of this review substantially. Another limitation is that in some countries over the past decade, since the publication of older TOM results, changes may have occurred in TB epidemiology, diagnosis (e.g. molecular techniques), treatment (e.g. individualised, better second-line drugs), supervision (i.e. admission, incentives) and surveillance, monitoring and reporting (e.g. electronic).

\section{Comparison with previous TOM reviews in the EU/EEA}

A previous systematic review in 2005 [39] of TOM in published articles from the WHO European region also showed availability of national estimates for only a limited number of countries, considerable heterogeneity and possible different interpretation given to WHO definitions, especially for unsuccessful outcomes. That review concluded that enhancement of national TB programmes is desirable, treatment characteristics should be more consistently reported and uniform interpretation of definitions should be promoted. According to a recent overview [3], the 30 EU/EEA member states present a highly heterogeneous situation in terms of TB epidemiology and control, distinguishing three broad epidemiological areas [38, 40]. Our review also reflects a highly heterogeneous picture of TOM outcomes in the EU. 
International systematic reviews into treatment outcomes of MDR-TB showed worse outcomes compared to fully susceptible $\mathrm{TB}$, as expected, with $62 \%$ of the pooled patients having a successful outcome. Also, high proportions of default and other unsuccessful outcomes were reported $[12,41]$. However, the majority of these reports were from middle- or highincidence countries outside the EU.

\section{Treatment outcome criteria}

Monitoring the outcome of treatment through a minimum set of outcome parameters is essential in order to evaluate the effectiveness of the intervention, i.e. a short-course anti-TB chemotherapy, and for comparison within and between countries [4]. Since 1998 the WHO/IUALTD consensus on standardised TOM categories and definitions for fully susceptible TB in Europe has existed [4,5], with updates [42], also in the context of the European framework for tuberculosis control and elimination in countries with a low incidence [43]. Although these TOM definitions are widely used in the literature, there are differences in the details that can affect the interpretation of the outcomes, and international comparability of results is still limited by insufficient standardisation $[38,39]$. Some countries use treatment outcome categories adapted from, but not similar to, the WHO and European standards. For example, the UK uses a modified set of definitions and does not use the category "default" but employs the categories treatment stopped (i.e. a patient found to have stopped treatment by themself for a reason not mentioned in other categories) or treatment not completed (no reason) (i.e. a patient was reported not to have completed treatment but the reason was unknown). In the published UK literature the presentation of these outcome categories varies, i.e. they are not shown as a uniform set of outcomes [14, 16, 21, 32]. An adjusted set of criteria, i.e. slightly modifying the WHO and European standards, was proposed from the UK for high-income low-incidence countries, especially those with a high mortality among elderly TB patients, more clinically appropriate for alterations in the management of patients. On these adjusted outcome categories successful outcomes in the UK increased from $77 \%$ to $88 \%$ [21].

Methods used to analyse the outcome of treatment for MDR-TB were standardised in 2005, enabling international comparisons [10]. Before the introduction of these definitions some countries experienced problems with the inadequate length of follow-up of 12 months for MDR-TB cases [10]. MDR-TB standard definitions were designed for cohort assignment (new MDR-TB, MDR-TB previously treated with only first-line drugs and MDR-TB previously treated with second-line drugs), patient categorisation (smear and culture conversion) and the six previously standardised treatment outcomes [4]. These definitions were used in the majority of the 14 reports from the six countries identified. One of the studies discussed the definitions from the perspective of overall programme performance evaluation in countries where MDR-TB treatment is fully integrated into programme practice [33]. In the Baltic states, the relatively high prevalence of primary MDR-TB contributed to low success rates [42], as indicated earlier for the WHO European region [41].

\section{Comparison with the central database}

24 out of $30 \mathrm{EU} / \mathrm{EEA}$ countries reported TOM data for 2008 [44] for culture-confirmed pulmonary TB to TESSy, compared to 22 for 2007 [3] and 21 for 2006. Five of the 24 reporting countries stated that $>10 \%$ of the cohort starting TB treatment had unknown outcomes. Treatment outcomes for MDR-TB after 24 months were reported by 15 countries for 2007 [3], and by the same 15 countries for 2008 [44]. Out of the six non-reporting countries for 2008 two (Liechtenstein and Luxembourg) represent only a small number of patients. The omission of TOM data from France, Greece, Italy and Spain is of greater concern. In a recent survey Luxembourg and Italy indicated that they do not collect data on TOM at the national level, while France and Spain reported that they collect TOM data at the national level [45]. It is not clear why these data are not reported to TESSy, but in the survey both France and Spain indicated difficulties with the completeness of the data. An interesting observation is that from Italy and Spain, indexed and non-indexed local, regional or sentinel studies on TOM are published from the AIPO-SMIRA (Italian Association of Hospital Pulmonologists-Italian Multicentre Study on Resistance to Antituberculosis Drugs) or National Tuberculosis Project network in Italy [46-49] or the Spanish Society of Pulmonology and Thoracic Surgery (SEPAR) network in Spain $[50,51]$.

\section{Treatment outcome in demographic or clinical subgroups in the population}

The published literature gave a fragmented and heterogeneous presentation of TOM data for demographic or clinical subgroups in the EU/EEA. For variables such as age group, pulmonary TB and MDR-TB, TESSy provides much more standardised and complete information and appears to be superior as a data source to systematic literature review and meta-analysis.

\section{Treatment outcome in vulnerable subgroups in the population}

Unsuccessful outcomes have been associated with socially excluded groups, such as some immigrants, asylum seekers, homeless persons, injecting drug users and alcoholics [39], and therefore data on these marginalised subgroups are relevant for TOM analysis.

This systematic review reflects that only a few of the included national studies, mostly retrospective, i.e. restricted to specific variables [27], published TOM data on marginalised subgroups in the population, often reporting a single outcome, i.e. death or default $[19,26,36]$. These limited data are probably incomplete and will not be representative for the EU. A recent survey demonstrated the availability of some variables relevant to TOM analysis of vulnerable subgroups in the EU/EEA in a reasonable number of member states, such as prisoners (17 countries) and asylum-seekers, drug addicts, alcoholics, undocumented persons and immunesuppressed patients (10-14 countries) [45].

In the EU/EEA undocumented migrants are a specific vulnerable group, often from high-endemic countries, which, in combination with a history of destitution, can result in high TB incidence rates. Because of eviction, e.g. a transfer in the context of the Dublin Agreement, they can contribute to a high proportion of unsuccessful outcomes because of unavailable final results [23].

TOM depends on the collaboration of local physicians who are more likely to cooperate to provide the requested information when it is simple, concise and of immediate obvious general interest [6]. Obtaining complete and uniform information on these risk factors will require a trade-off of expansion of routine 
surveillance versus limiting the collected data to a minimum, especially in those low-incidence countries where TB services are generally an integrated part of the overall healthcare system, rather than a distinct specialised programme or service [16, 21, 52]. To answer more complex questions on vulnerable subpopulations specifically designed surveys have been advised [6].

Further consideration should be given to TOM data collection in socially marginalised groups in the EU/EEA countries allowing more standardised and complete analysis of treatment outcomes, preferably including reporting of TOM in vulnerable population groups in national reports and to TESSy.

\section{TOM critical issues}

This literature review did not provide extensive information on critical TOM issues, gaps and challenges. A limited number of publications gave some suggestions for improvements. Main critical issues identified related to the TOM system were registration of mortality in the elderly and registration of failure. Critical issues have been addressed in detail in a separate report presented to ECDC [45].

\section{Conclusion}

Surveillance is an integral part of TB control, its contribution is essential to inform the programme on what is going on and what public health response is urgently needed but it is still suboptimal in Europe [53,54]. Standardised routine reporting under harmonised definitions and outcome categories to a centralised database is key for an EU-wide surveillance system, including TOM, as well as challenges to improve completeness, timeliness, comparability and trend analysis.

Our systematic review indicates that PubMed/MEDLINE and EMBASE indexed studies are not a suitable instrument to describe TOM processes, methods, policies and practices. They do not produce TOM results representative for the general population or for demographic, clinical and social subgroups in the $30 \mathrm{EU} / \mathrm{EEA}$ countries. They provide little information on useful TOM variables not available in TESSy. TESSy should portray the most representative picture of $\mathrm{TB}$ treatment outcomes in the EU/EEA, providing all countries report TOM data annually, guided by ECDC and national focal institutes, and based on standardised and complete local data collection. While TESSy focuses on routine TOM in the general population, the treatment outcome of cases among specific marginalised and vulnerable subgroups, some available in EU/EEA countries' TB registers, are of specific public health importance and general public health interest, and thus relevant for publication in peer-reviewed journals.

\section{SUPPORT STATEMENT}

This study was funded by the European Centre for Disease Prevention and Control under contract ECDC.2165.

\section{STATEMENT OF INTEREST}

None declared.

\section{REFERENCES}

1 European Centre for Disease Control. Framework Action Plan to Fight Tuberculosis in the European Union. http:/ /ecdc.europa.eu/ en/publications/Publications/0803_SPR_TB_Action_plan.pdf Date last accessed: 2011. Date last updated: February 2008.
2 Fernandez de la Hoz K, Manissero D. A framework action plan to fight tuberculosis in the European Union. Eurosurveillance 2008; 18: 13.

3 Manissero D, Hollo V, Huitric E, et al. Analysis of tuberculosis treatment outcomes in the European Union and European Economic Area: efforts needed towards optimal case management and control. Eurosurveillance 2010; 18: 15.

4 Veen J, Raviglione M, Rieder HL, et al. Standardized tuberculosis treatment outcome monitoring in Europe. Recommendations of a Working Group of the World Health Organization (WHO) and the European Region of the International Union Against Tuberculosis and Lung Disease (IUATLD) for uniform reporting by cohort analysis of treatment outcome in tuberculosis patients. Eur Respir J 1998; 12: 505-510.

5 World Health Organization. Treatment of Tuberculosis. Guidelines for National Programmes. WHO Report 2003. Document WHO/ CDS/TB 2003/313. www.emro.who.int/stb/media/pdf/2003.313. pdf Date last accessed: 2011. Date last updated: 2003.

6 Rieder HL, Watson JM, Raviglione MC, et al. Surveillance of tuberculosis in Europe. Working Group of the World Health Organization (WHO) and the European Region of the International Union Against Tuberculosis and Lung Disease (IUATLD) for uniform reporting on tuberculosis cases. Eur Respir J 1996; 9: 1097-1104.

7 Commission Decision of 28 April 2008 amending Decision 2002/ 253/EC laying down case definitions for reporting communicable disease to the Community network under Decision No 2119/98EC of the European parliament and of the Council (notified under document number C(2008)1589). http:/ /eur-lex.europa.eu/ LexUriServ / LexUriServ.do?uri=OJ:L:2008:159:0046:0090:EN:PDF Date last accessed: 2011. Date last updated: April 2008.

8 Pai M, McCulloch M, Gorman JD, et al. Systematic reviews and meta-analyses: an illustrated, step-by-step guide. Nat Med J India 2004; 17: 86-95.

9 European Centre for Disease Prevention and Control/WHO Regional Office for Europe Tuberculosis surveillance in Europe 2008. Stockholm, European Centre for Disease Prevention and Control, 2010. www.euro.who.int/_data/assets/pdf_file/0007/ 78856/E93600.pdf Date last accessed: 2011. Date last updated: 2010.

10 Laserson KF, Thorpe LE, Leimane $\mathrm{V}$, et al. Speaking the same language: treatment outcome definitions for multidrug-resistant tuberculosis. Int J Tuberc Lung Dis 2005; 9: 640-645.

11 World Health Organization Guidelines for the programmatic management of drug-resistant tuberculosis emergency update 2008. Geneva, WHO, 2008. http://whqlibdoc.who.int/publications /2008/9789241547581_eng.pdf Date last accessed: 2011. Date last updated: 2008.

12 Johnston JC, Shahidi NC, Sadatsafavi M, et al. Treatment outcomes of multidrug-resistant tuberculosis: a systematic review and metaanalysis. PLoS One 2009; 4: e6914.

13 Abubakar I, Moore J, Drobniewski F, et al. Extensively drug-resistant tuberculosis in the UK: 1995 to 2007. Thorax 2009; 64: 512-515.

14 Abubakar I, Laundy MT, French CE, et al. Epidemiology and treatment outcome of childhood tuberculosis in England and Wales: 1999-2006. Arch Dis Child 2008; 93: 1017-1021.

15 Anderson LF, Laurenson IF, Blatchford $\mathrm{O}$, et al. Trends in multidrug-resistant tuberculosis in Scotland, 2000-7. Eurosurveillance 2009; 19: 14.

16 Antoine D, French CE, Jones J, et al. Tuberculosis treatment outcome monitoring in England, Wales and Northern Ireland for cases reported in 2001. J Epidemiol Community Health 2007; 61: 302-307.

17 Bang D, Andersen AB, Thomsen VO, et al. Recurrent tuberculosis in Denmark: relapse vs. re-infection. Int J Tuberc Lung Dis 2010; 14: 447-453.

18 Bang D, Lillebaek T, Thomsen VO, et al. Multidrug-resistant tuberculosis: treatment outcome in Denmark, 1992-2007. Scand J Infect Dis 2010; 42: 288-293. 
19 Borgdorff MW, Veen J, Kalisvaart NA, et al. Defaulting from tuberculosis treatment in The Netherlands: rates, risk factors and trend in the period 1993-1997. Eur Respir J 2000; 16: 209-213.

20 Bwire R, Nagelkerke N, Keizer ST, et al. Tuberculosis screening among immigrants in The Netherlands: what is its contribution to public health? Neth J Med 2000; 56: 63-71.

21 Ditah IC, Reacher M, Palmer C, et al. Monitoring tuberculosis treatment outcome: analysis of national surveillance data from a clinical perspective. Thorax 2008; 63: 440-446.

22 Falzon D, Scholten J, Infuso A. Tuberculosis outcome monitoring is it time to update European recommendations? Eurosurveillance 2006; 11: 20-25.

23 Farah MG, Tverdal A, Steen TW, et al. Treatment outcome of new culture positive pulmonary tuberculosis in Norway. BMC Public Health 2005; 5: 14.

24 Geerligs WA, Van Altena R, De Lange WCM, et al. Multidrugresistant tuberculosis: long-term treatment outcome in the Netherlands. Int J Tuberc Lung Dis 2000; 4: 758-764.

25 Holtz TH, Sternberg M, Kammerer S, et al. Time to sputum culture conversion in multidrug-resistant tuberculosis: predictors and relationship to treatment outcome. Ann Intern Med 2006; 144: 650-659.

26 Kliiman K, Altraja A. Predictors and mortality associated with treatment default in pulmonary tuberculosis. Int J Tuberc Lung Dis 2010; 14: 454-463.

27 Kliiman K, Altraja A. Predictors of poor treatment outcome in multi- and extensively drug-resistant pulmonary TB. Eur Respir J 2009; 33: 1085-1094.

28 Leimane V, Riekstina V, Holtz $\mathrm{TH}$, et al. Clinical outcome of individualised treatment of multidrug-resistant tuberculosis in Latvia: a retrospective cohort study. Lancet 2005; 365: 318-326.

29 Lockman S, Kruuner A, Binkin N, et al. Clinical outcomes of Estonian patients with primary multidrug-resistant versus drugsusceptible tuberculosis. Clin Infect Dis 2001; 32: 373-380.

30 Marica C, Didilescu C, Galie N, et al. Reversing the tuberculosis upwards trend: a success story in Romania. Eur Respir J 2009; 33: 168-170.

31 Nathanson E, Lambregts-van Weezenbeek C, Rich ML, et al. Multidrug-resistant tuberculosis management in resource-limited settings. Emerg Infect Dis 2006; 12: 1389-1397.

32 Ormerod LP, Prescott RJ. The management of pulmonary and lymph node tuberculosis notified in England and Wales in 1998. Clin Med 2003; 3: 57-61.

33 Riekstina $\mathrm{V}$, Leimane $\mathrm{V}$, Holtz $\mathrm{TH}$, et al. Treatment outcome cohort analysis in an integrated DOTS and DOTS-Plus TB program in Latvia. Int J Tuberc Lung Dis 2007; 11: 585-587.

34 Romanus V, Julander I, Blom-Bülow B, et al. Det finns brister inom den svenska tuberkulosvården: fullgott resultater efter tolv månader hos endast 71 procent visar aktuell studie. [Shortages in Swedish tuberculosis care. Good results only in 71 percent of cases after 12-month treatment as shown in a current study]. Lakartidningen 2000; 97: 5613-5616.

35 Trnka L, Dankova D, Krejbich F. Is quarterly cohort analysis useful for assessing treatment outcomes in a low incidence country? Int $J$ Tuberc Lung Dis 2001; 5: 250-256.

36 Vasankari T, Holmstrom P, Ollgren J, et al. Risk factors for poor tuberculosis treatment outcome in Finland: a cohort study. BMC Public Health 2007; 7: 291.
37 Leimane V. Treatment and management of MDR-TB in Latvia. Bull World Health Organ 2007; 85: 393-394.

38 Falzon D, Ait-Belghiti F. What is tuberculosis surveillance in the European Union telling us? Clin Infect Dis 2007; 44: 1261-1267.

39 Faustini A, Hall AJ, Perucci CA. Tuberculosis treatment outcomes in Europe: a systematic review. Eur Respir J 2005; 26: 503-510.

40 Infuso A, Falzon D. World Stop TB Day 2005: Tuberculosis Care Providers and Monitoring the Treatment Outcome in Europe. Eurosurveillance 2005; 10: E050324.2.

41 Orenstein EW, Basu S, Shah NS, et al. Treatment outcomes among patients with multidrug-resistant tuberculosis: systematic review and meta-analysis. Lancet 2009; 9: 153-161.

42 World Health Organization, International Union against Tuberculosis and Lung Disease, Royal Netherlands Tuberculosis Association. Revised international definitions in tuberculosis control. Int J Tuberc Lung Dis 2001; 5: 213-215.

43 Broekmans JF, Migliori GB, Rieder HL, et al. European framework for tuberculosis control and elimination in countries with a low incidence. Recommendations from the World Health Organisation (WHO), International Union against Tuberculosis and Lung Disease (IUATLD) and Royal Netherlands Tuberculosis Association (KNCV) Working Group. Eur Respir J 2002; 19: 765-775.

44 European Centre for Disease Prevention and Control/WHO Regional Office for Europe. Tuberculosis Surveillance in Europe 2009. www.ecdc.europa.eu/en/publications/Publications/1103_TB _SUR_2009.pdf Date last accessed: 2011. Date last updated: March 2011.

45 Verver S, Van Hest R, Slump E, et al. Enhancing Treatment Outcome Monitoring of Tuberculosis Cases at EU level. Report to ECDC (ECDC.2165). The Hague, KNCV Tuberculosis Foundation, 2011.

46 Migliori GB, Ambrosetti M, Besozzi G, et al. Microbiological confirmation of tuberculosis cases at diagnosis and at the end of treatment in Italy. Eur J Epidemiol 2000; 168: 719-724.

47 Centis R, Ianni A, Migliori GB. Evaluation of tuberculosis treatment results in Italy, report 1998. Tuberculosis section of the National AIPO Study Group on Infectious Disease and the SMIRA Group. Monaldi Arch Chest Dis 2000; 55: 293-298.

48 Centis R, Migliori GB. Evaluation of tuberculosis treatment results in Italy, report 1999. Monaldi Arch Chest Dis 2002; 57: 297-305.

49 Ferrara G, Richeldi L, Bugiani M, et al. Management of multidrug-resistant tuberculosis in Italy. Int J Tuberc Lung Dis 2005; 9: 507-513.

50 Cayla JA, Caminero JA, Rey R, et al. Current status of treatment completion and fatality among tuberculosis patients in Spain. Int $J$ Tuberc Lung Dis 2004; 8: 458-464.

51 Cayla JA, Rodrigo T, Ruiz-Manzano J, et al. Tuberculosis treatment adherence and fatality in Spain. Respir Res 2009; 10: 121.

52 Rose AM, Gatto AJ, Watson JM. Recent increases in tuberculosis notifications in England and Wales - real or artefact. J Public Health Med 2002; 24: 136-137.

53 D'Ambrosio L, Centis R, Spanevello A, et al. Improving tuberculosis surveillance in Europe is key to controlling the disease. Eurosurveillance 2010; 15: 19513.

54 Ködmön C, Hollo V, Huitric E, et al. Multidrug- and extensively drug-resistant tuberculosis: a persistent problem in the European Union and European Economic Area. Eurosurveillance 2010; 15: 19519. 